\title{
Fijar la memoria visual ${ }^{1}$
}

\author{
Luis Carlos Toro Tamayo² \\ Escuela Interamericana de Bibliotecología, Universidad de \\ Antioquia-UdeA, Medellín, Colombia
}

Resumen: Las imágenes ocupan gran parte de nuestras vidas. Cada vez que realizamos una acción, a veces trascendental, otras en cambio cotidianas, buscamos fijarla en algún soporte con el objetivo de preservar el instante. Con el tiempo esos instantes conformaran nuestros archivos de recuerdos. La manera en la que guardamos esos recuerdos hablará de la importancia de ese momento que quedó cristalizado en el tiempo y que hoy pasa a ser nuestra memoria personal. El presente texto nos explicará la relación entre memoria y fotografía y como esta relación pueden aportar al esclarecimiento de la verdad, la justicia y la reparación por parte del Estado.

Palabras clave: Fotografía; Memoria; Derechos humanos.

Título: Fixar a memória visual

Resumo: As imagens ocupam grande parte de nossas vidas. Cada vez que realizamos uma ação, às vezes transcendental, outras, ao contrário, cotidianas, procuramos fixá-la em algum suporte com o objetivo de preservar o instante. Com o tempo, esses instantes conformarão nossos arquivos de recordações. A maneira como guardamos essas recordações falará da importância desse momento que ficou cristalizado no tempo e que hoje passa a ser nossa memória pessoal. O presente texto irá nos explicar a relação entre memória e fotografia e como essa relação pode contribuir para o esclarecimento da verdade, a justiça e reparação por parte do Estado.

Palavras-chave: Fotografia; Memória; Direitos humanos.

Title: To set visual Memory

Abstract: Images occupy a large part of our lives. Every time we carry out an action, sometimes transcendental, sometimes daily, we seek to fix it on some support in order to preserve the moment. Over time those moments will shape our memory archives. The way in which we keep those memories will talk about the importance of that moment that was crystallized in time and that today becomes our personal memory. This text will explain

\footnotetext{
${ }^{1}$ El presente texto es un avance del proyecto "Puntos de encuentro entre las memorias inscritas y las memorias vivas", de la línea Memoria y Sociedad del Grupo de Investigación en Información, Conocimiento y Sociedad. Actualmente cuenta el apoyo de la Organización Caminos de Esperanza Madres de La Candelaria, con la cofinanciación del Museo de Arte Moderno de Medellín, la Escuela de Ciencias Sociales de la Universidad Pontificia Bolivariana y la Université de Lorraine, y recibe aportes del CICINF de la Escuela Interamericana de Bibliotecología de la Universidad de Antioquia. UdeA, Calle 70 No. 52 - 21, Medellín - Colombia.

${ }^{2}$ Doctor en Langues et Littératures Romanes y doctor en Estudios Latinoamericanos de l'Université Paris Ouest Nanterre La Défense y la Universidad de Chile, magister en Lingüística e historiador de la Universidad de Antioquia. Profesor Escuela Interamericana de Bibliotecología, Universidad de Antioquia UdeA, Calle 70 \# 52 21, Medellín - Colombia. Orcid: http://orcid.org/0000-0003-1793-8751

E-mail: Icarlos.toro@udea.edu.co
} 
the relationship between memory and photography and how this relationship can contribute to the clarification of truth, justice and reparation by the State.

Keywords: Photography; Memory; Human rights.

\section{Presentación}

Para entender la relación que se da entre las imágenes y la memoria, abordaremos la fotografía como dispositivo de recuerdo, sus usos y sus posibilidades en la reconstrucción del pasado. Luego analizaremos la fotografía como documento y su incidencia en temas relacionados con la justicia y el esclarecimiento de la verdad, y finalmente analizaremos los casos de dos asociaciones que luchan por la defensa de sus derechos y utilizan la fotografía como parte de sus instrumentos de validación, denuncia y lucha política.

Este recorrido nos permitirá entender las imágenes, no solo desde una lectura culturalista (SONTAG, 2005; WARBURG, 2010; WILLIAMS, 2000), si no como instrumento ideológico de control (VAN DIJK, 2003), y como sistema de pensamiento (González Cuesta, 2010). Así mismo, estudiaremos la imagen como documento, tanto en su formato, como en sus parametrizaciones (AUTOR CORPORATIVO, 2002; GIRALDO-LOPERA et al., 2014; Solórzano-Ariza et Al, 2017). El último apartado nos mostrará la relación entre imágenes y memoria, como se construyen estos discursos, su mediatización y sus apuestas por la búsqueda de la verdad (GIRALDO-LOPERA et al., 2015, 2018; MACHADO DA SILVEIRA, 2018).

\section{El recuerdo en imágenes}

"Las representaciones en imágenes han ingresado a la investigación social con sentidos múltiples: como fuentes de datos, como objetos de estudio, como indicios de climas culturales de épocas, de mentalidades y de sistemas de significación" (JELIN, 2012, p. 55). Este cambio se presentó en Colombia en 2002 a partir de la implementación del Formato Único de Inventario Documental - Material Fotográfico, expedido por el Archivo General de la Nación (AUTOR CORPORATIVO, 2002). La nueva disposición considera a la imagen fotográfica como documento oficial, convirtiéndose en fuente de consulta independiente del registro escrito.

Sin embargo, al momento de analizar una fotografía debemos tener en cuenta múltiples factores que intervienen. Desde la obturación, los ángulos, los encuadres, y demás asuntos relacionados con la técnica, hasta los factores económicos, las coyunturas políticas y los aspectos hegemónicos y contra hegemónicos que se desarrollan en la sociedad (Williams, 2000, Pp. 129-136). Dichos cambios en la mirada son reconocidos por Sontag como una "gramática y, sobre todo, una ética de la visión" (2005, p. 15), y por Warburg como el "poder que tiene los símbolos de activar el recuerdo" (2010, p. 206). Según Jelin: 
La fotografía es vista como modelo de veracidad y objetividad. Sabemos sin embargo, que la fotografía no es un reflejo o una representación directa e inmediata de ninguna realidad. Capta un momento, pero, además, no desde un lugar objetivo y neutro, sino desde el lugar, la mirada y la selección hecha por el (la) fotógrafo(a), desde su punto de vista (JELIN, 2012, p. 58).

Desde las Ciencias de la Información existen elementos que aportan en la descripción de los documentos en tanto definen su naturaleza, el tipo de institución que la produjo, el tiempo de creación, el espacio, etc. Un elemento central en este proceso de organización y registro de la información es el contexto de producción. El contexto de producción es una pieza clave en la construcción de la memoria, considerando que este se complementa con fuentes documentales asociadas a la fotografía tales como el testimonio y los soportes asociados a la imagen. Dicho contexto le da valor documental a la fotografía elevándola a la condición de prueba, instrumento y registro del pasado. No obstante, para Didi Huberman existen factores que nos hacen dudar de la veracidad de las imágenes:

(...) nos encontramos frecuentemente enfrascados en el inmenso y rizomático archivo de imágenes heterogéneas que resulta difícil manejar, organizar y entender, precisamente porque su laberinto está hecho tanto de intervalos y de lagunas como de cosas observables. Intentar una arqueología es siempre asumir el riesgo de poner, unos junto a otros, fragmentos de cosas sobrevivientes, necesariamente heterogéneas y anacrónicas debido a que proceden de sitios separados y de tiempos separados por lagunas. Ahora bien, ese riesgo tiene dos nombres: imaginación y montaje (DIDI HUBERMAN, 2012, p. 20).

En archivística, más que imaginación se requiere del acopio de materiales probatorios que demuestren la veracidad de los soportes documentales, y más que montaje, consideramos los factores externos, el lugar de enunciación de la imagen; es decir quién y porqué fue tomada la fotografía, y qué se quiso decir con esta imagen, para evidenciar mejor el contexto de producción de la fotografía. Lo anterior para evidenciar que la imagen fotográfica es tan solo un fragmento del pasado. Es decir, un instante en el que se muestran situaciones y hechos que nos permiten entender esos pasados, los cuales están limitados por el formato fotográfico, es decir, el marco y el lente que se utilice, y por el punto de vista de quien realiza la fotografía. Según Sontag:

El fotógrafo era tenido por un observador agudo pero imparcial: un escriba, no un poeta. Pero como la gente pronto descubrió que nadie retrata lo mismo de la misma manera, la suposición de que las cámaras procuran una imagen objetiva e impersonal cedió ante el hecho de que las fotografías no sólo evidencian lo que hay allí sino lo que un individuo ve, no son sólo un registro sino una evaluación del mundo (SONTAG, 2005, pp. 129-130).

Entender o tener datos sobre la forma en la que se construye la imagen nos permite elaborar el contexto en el que se enmarca la fotografía, aportando información relevante que orienta a los observadores. De quienes organizan la información documental dependerá la manera en la que se registra la información contextual del documento. La elaboración de un 
contexto enmarcada en un proceso de investigación riguroso sobre los lugares, los tiempos, las situaciones presentadas dentro y fuera del campo visual de la fotografía, los descriptores visuales, y demás registros que se conserven de la imagen, aportará elementos claves en la interpretación de la imagen como documento histórico.

\section{Documentos visuales de memorias en duelo}

La fotografía interpreta lo real, no es solo imagen como la pintura o el grabado. Usurpa la realidad, es una huella del pasado, un rastro del tiempo. Las imágenes tienen un poder extraordinario, incluso hay realidades que tenemos como imágenes y que hacen parte de un discurso colectivo que nos pertenece a todos. Lugares, personajes, incluso imaginarios son parte del repertorio de representaciones visuales que nos muestran pedazos de la historia de la humanidad.

Sin embargo, algunos afirman que la fotografía miente, es montaje, copia, duplicadora de realidades, pero también es una extensión del tema tratado. No se limita a rendirle culto a esa parte de la realidad fotografiada, sino que es un nuevo documento que complementa y permite ampliar la mirada de los hechos. La cámara como instrumento con sentidos múltiples: como copiadora, como constructora, como interprete. El fotógrafo como escriba, como observador, como mensajero.

\footnotetext{
Toda fotografía es una ficción que se presenta como verdadera. Contra lo que nos han inculcado, contra lo que solemos pensar, la fotografía miente siempre, miente por instinto, miente porque su naturaleza no le permite hacer otra cosa. Pero lo importante no es esa mentira inevitable. Lo importante es cómo la usa el fotógrafo, a qué intenciones sirve. Lo importante, en suma, es el control ejercido por el fotógrafo para imponer una dirección ética a su mentira. El buen fotógrafo es el que miente bien la verdad (FONTCUBERTA, 1997, p. 15).
}

De acuerdo a lo referido, qué opinión tenemos frente a una imagen donde el tema central sea el dolor, la representación fotográfica del desaparecido, el ritual de duelo de los familiares que portan dicha imagen y denuncian mediante un performánce la injusticia. Para Rancière (2010, p. 97), la imagen intolerable es aquella que se apoya en situaciones de horror humanitario, pero que solo se activa por el vínculo del espectador con el contexto político que la contiene y por el sentimiento de repudio frente a los hechos atroces que aparecen representados.

Cuando analizamos piezas fotográficas con estas características, debemos entender que este tipo de información es producida por un individuo, o por un grupo de personas que buscan denunciar frente al Estado sus situaciones de vulnerabilidad. En dichos casos la fotografía define usos sociales que plantean un reto para el analista. Entre los usos más recurrentes está el simbólico, que subyace en la subjetividad de quien capta el instante, así como en los factores emocionales y sociales que hacen de esta toma algo especial. 
Una experiencia vivida subjetivamente y compartida culturalmente por una sociedad que se apropia de símbolos culturales para construir materiales que con el tiempo pasarán a ser vehículos de la memoria. Estos vehículos los vemos en museos, en libros, en monumentos, en películas, en tejidos testimoniales y demás objetos y acciones performáticas, que representan mediante actuaciones y expresiones un pasado que necesita ser narrado para confrontar el presente.

Otro uso que podemos encontrar en la fotografía como documento es el político. Los casos en los que se dan este tipo de usos están relacionados con situaciones límites en los que la sociedad se ve obligada a hacer pública su inconformidad denunciando los hechos que los convirtieron en víctimas. Este tipo de representaciones se observa en imágenes que hacen evidentes situaciones en la que fueron vulnerados sus derechos civiles. También lo vemos en situaciones en los que la imagen del rostro de un individuo es usada como dispositivo de recuerdo. Para Da Silva Catela (2017), los usos de la imagen en el caso de represión, desaparición y muerte de Santiago Maldonado, activista que participaba en el corte de la ruta 40 en Cushamen, en reclamo por la lucha de la tierra ancestral del pueblo Mapuche, nos advierten sobre el poder de las imágenes y sus múltiples posibilidades como instrumento político de denuncia.

\footnotetext{
Un Estado que asesina en nombre de la civilización. Una sociedad que muestra esos rostros para reclamar por sus vidas y su memoria. Allí donde el Estado depredó, arrasó y destruyó, la fotografía de los rostros de estos jóvenes y su poder simbólico, aparecen para subrayar el rechazo a la violencia, oponerse a ella y generar pequeños y profundos rituales de verdad y justicia (DA SILVA CATELA, 2017, p. 50).
}

En este caso específico, el rostro de este activista se hizo presente en páginas de Facebook, en carteles, en hojas volantes, en camisetas, en paredes, en pancartas y en marchas, entre otras. Lógicamente hubo confrontaciones emocionales de diferentes tipos: la de sus familiares que lo descubren en sus acciones como activista; la de la sociedad que se identifica con el Santiago campesino, trabajador y artista; y la imagen propia que se presenta como un personaje vinculado a causas y acciones de resistencia.

Finalmente, el uso documental de la imagen fotográfica nos permite ubicar este tipo de hechos en un tiempo y un espacio, y hacer de ellas parte de las evidencias probatorias que se requieren en las cadenas de custodia de la legislación nacional. Desde las legislaciones vigentes en Colombia tenemos: Ley General de Archivos (2000); la de Justicia y Paz (2005); la de Víctimas y Restitución de Tierras (2011), y la de Transparencia y del Derecho de Acceso a la Información Pública Nacional (2014). Este tipo de acciones de reparación están siendo efectivas con las nuevas disposiciones normativas y las imágenes, como documentos oficiales dentro de la reglamentación, constituyen un eslabón más en la defensa de los derechos humanos. 


\section{La imagen en la lucha por la defensa de los derechos humanos}

A partir del trabajo con organizaciones que defienden sus derechos civiles frente al Estado, hemos construido un proceso pedagógico en el que las personas que integran estos colectivos han aprendido a reconocer el valor de sus archivos y los uso que le pueden dar a sus fotografías como objetos simbólicos, como dispositivos para la denuncia o como evidencia o garantía de derechos. Analicemos las siguientes imágenes que hicieron parte del resultado de un proceso de intercambio de experiencias entre un grupo de investigadores y las integrantes de la Asociación Caminos de Esperanza Madres de La Candelaria. De dicho proceso obtuvimos una información que derivó en la construcción de un guión museográfico (Giraldo et al., 2014), realizamos dos libros (Giraldo et al., 2015, 2018) y dos exposiciones (Archivo Vivo: Memorias de Madres, 2016, 2017. Adicionalmente quedó registro de un recorrido virtual en el que se pueden apreciar las piezas que resultaron de esta construcción colectiva (Exposición virtual MCM (2016).

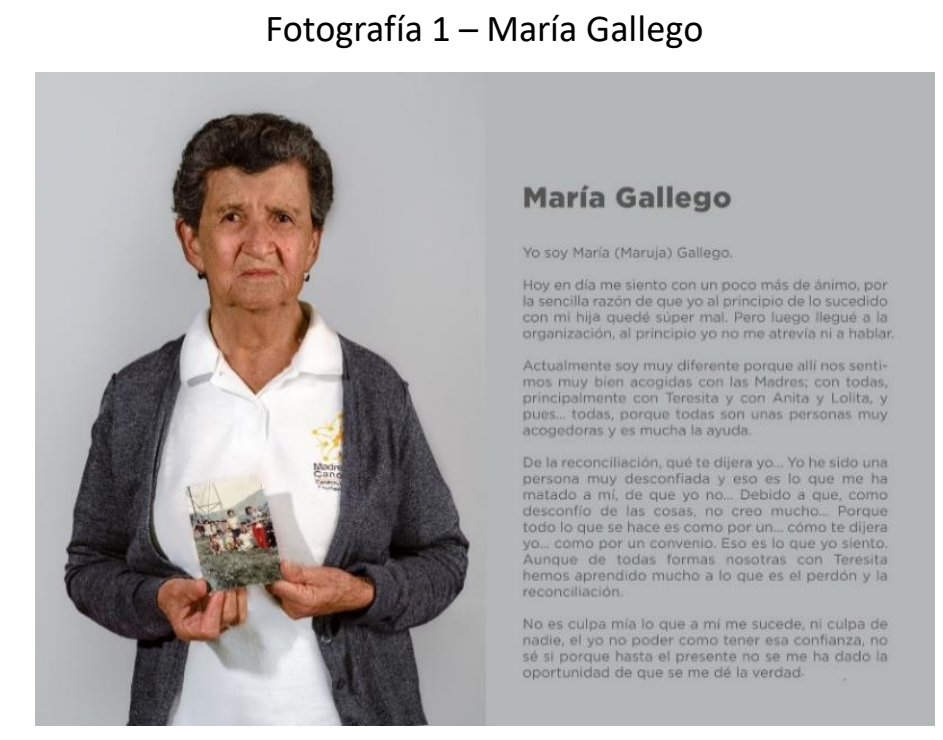

Fotografía 2 - Teresita Gaviria

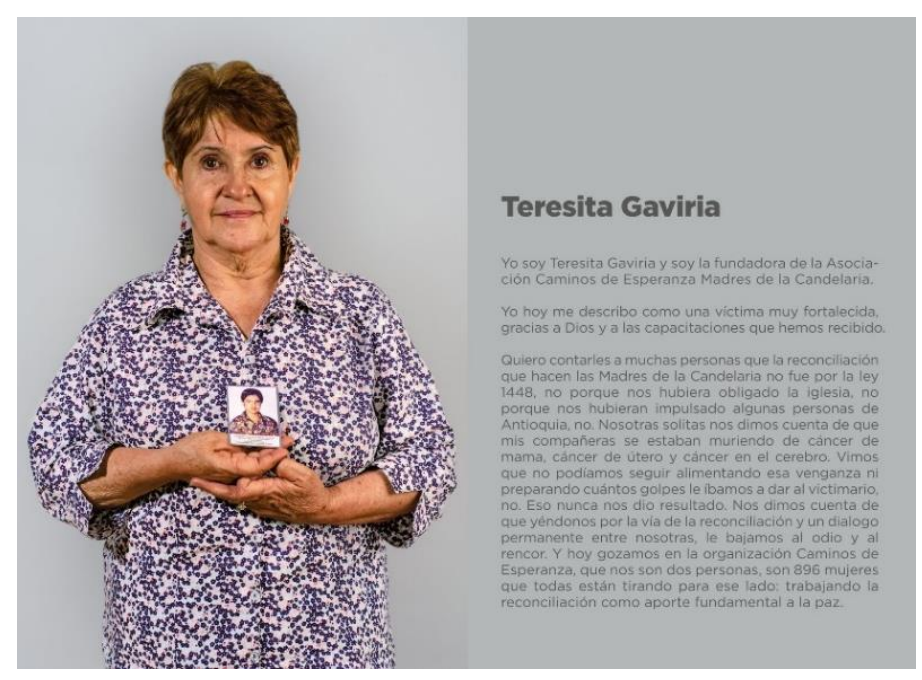


En estas dos imágenes, en las que aparecen de arriba abajo las señoras María Gallego (Fotografía 1) y Teresita Gaviria (Fotografía 2), ambas integrantes y líderes de la Asociación Caminos de Esperanza Madres de La Candelaria, observamos un discurso emotivo que busca hacer evidente la ausencia y el duelo, y que representa su manera de tramitar el dolor. En dicho ejercicio estas mujeres portan fotografías con el objetivo de denunciar su pérdida mediante la construcción de un dispositivo que hace visible a las víctimas del Conflicto Armado en Colombia. Aquí, las imágenes hacen parte de un montaje en el que dichas mujeres aparecen sujetando las fotografías de sus hijos en un gesto desafiante que las convierte en agentes portadoras de unas memorias que son narradas con su propia voz. Tal y como lo aclaramos, este acto de valentía hace parte de un discurso museográfico construido con ellas, por ellas y para ellas, como una manera de mostrar las formas de lucha y el tipo de dispositivos que se pueden usar para tales fines.

Así mismo, estos colectivos construyen otros discursos performáticos en los que también son utilizadas las fotografías como estrategia de denuncia. Existen imágenes estampadas en camisetas, en carteles para salir a marchar, construyen altares, y un sin número de formas de insistir en el recuerdo de sus familiares mediante acciones de resistencia, insistencia y persistencia. En la siguiente imagen (Fotografía 3), observamos a las Madres de La Candelaria portando las fotografías de sus familiares desaparecidos en un acto cultural que dignifica sus memorias. Así mismo, en la imagen de la derecha (Fotografía 4), observamos uno de los carteles utilizados en sus marchas o plantones que realizan sin descanso todos los jueves a las afueras de la iglesia La Candelaria en el centro de la ciudad de Medellín - Colombia.

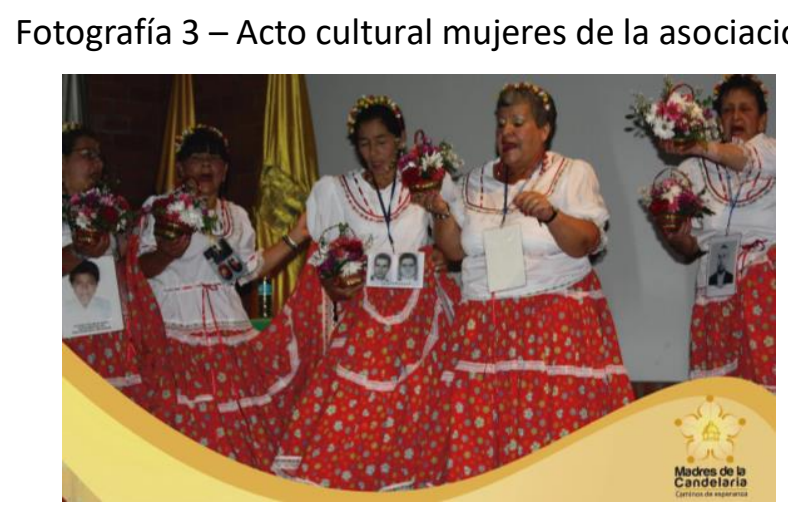

Fotografía 4 - Cartel o Pasacalles de la Asociación

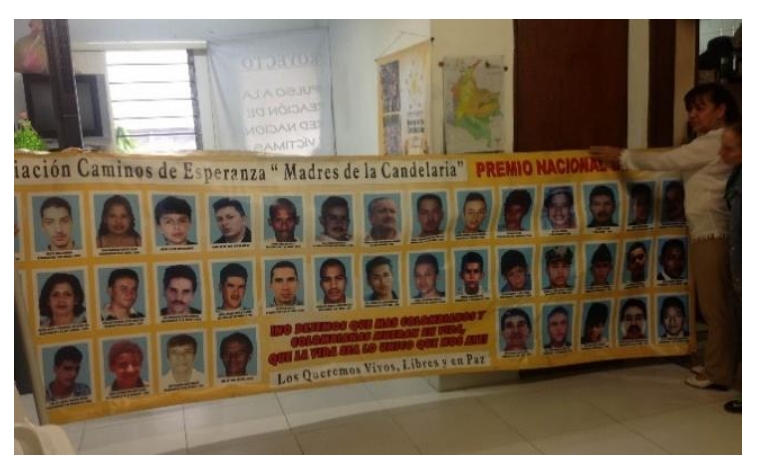


Imágenes como estas son comunes y se repiten en diferentes contextos como una forma clara de resistencia política. En los primeros gestos de rechazo a las acciones violentas aparecen las fotografías de las víctimas como una respuesta instintiva frente a la perdida. Altares espontáneos instalados en los lugares de los hechos advierten al anónimo transeúnte sobre lo ocurrido. Los rostros de los desparecidos que comienzan a habitar los espacios de memoria instalan en la sociedad un mensaje contundente.

Además de las imágenes, la mayoría de las veces también observamos acciones performáticas que acompañan estos rituales de duelo. Llevar una imagen colgada sobre el cuello como un relicario o hacer un cartel con el rostro de las víctimas para salir a marchar, nos recuerda el pasaje bíblico que relata la escena en la que una mujer cubre el rostro ensangrentado de cristo, el cual queda plasmado milagrosamente en la tela. Al realizar esta acción, la Santa Verónica nos revela la imagen de quien sufre, de quien enfrente la más grande injusticia, de una víctima que no merece este destino.

Para Taylor (2016): estas acciones, estos rituales, estas manifestaciones públicas, entre otras, producen un conocimiento y una serie de informaciones que hacen parte del devenir de las organizaciones y constituyen las memorias vivas que complementan el registro archivístico. Otro caso emblemático que nos ha permitido reflexionar sobre el papel de la fotografía en la construcción de la memoria es el de las Víctimas de la Discoteca Kiss. El 27 de enero de 2013, a las 2:30 de la madrugada en el local número 1925 en la Rua dos Andradas, en el centro de Santa Maria en el estado brasileño de Rio Grande do Sul, un incendio consumió el establecimiento que acabó con la vida de 239 jóvenes y dejó heridos a otros 124 en un hecho siniestro que se conoce como la tragedia de la discoteca Kiss.

En este infame episodio, propiciado por el descuido de los administradores del lugar y la falta de políticas claras en la regulación de los establecimientos públicos por parte de las autoridades, quedaron diezmadas las vidas de toda una generación de jóvenes universitarios. La respuesta de los familiares a este hecho fue crear altares y mantener viva la memoria de sus hijos mediante acciones legales y representaciones visuales como la instalada en la plaza principal de Santa Maria, justo al frente de la intendencia. Allí, un grupo de madres y padres de los protagonistas de la catástrofe continúan honrando sus memorias y defendiendo sus derechos con el ánimo no solo de ser reparados por el Estado, sino de hacer justicia y juzgar a los responsables. 
Fotografía 5 - tienda de la vigilia

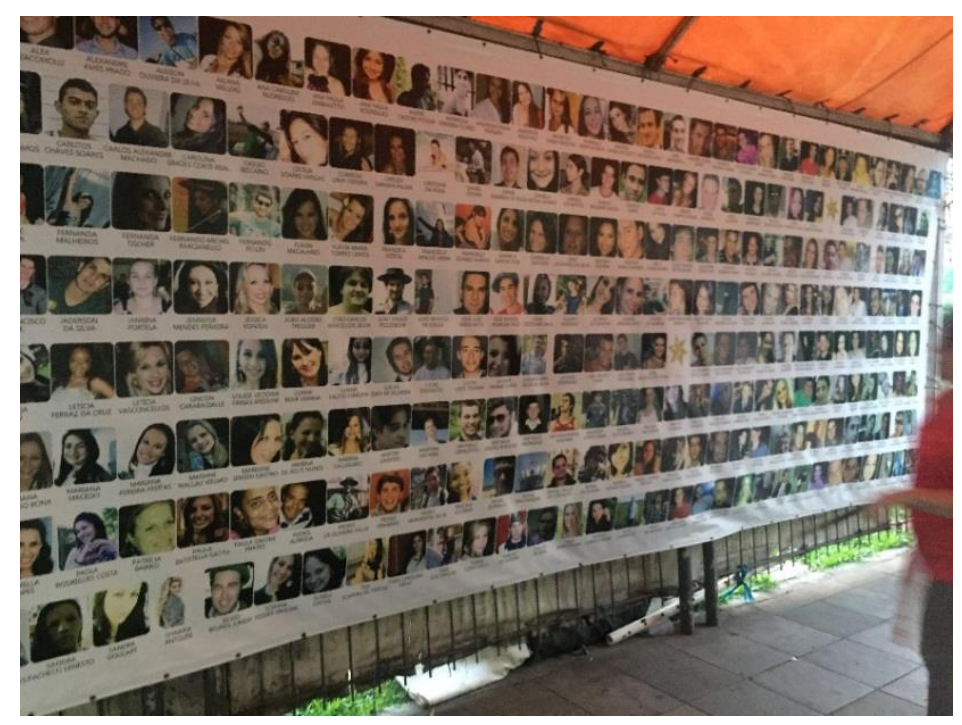

La forma de crear estas memorias fue desde el principio a través de las imágenes. Este dispositivo de memoria ha construido una presencia indeleble que incluso ha generado descontento entre algunos familiares de las víctimas, quienes consideran que es mejor seguir adelante. Otros sin embargo continúan insistiendo en su lucha y reclamando justicia a un Estado que los ignora y los relega al olvido. En la "tienda de la vigilia", nombre asignado por la misma asociación, los familiares de las víctimas continúan haciendo plantones para reclamar justicia y promover entre los jóvenes un mensaje de conciencia frente a sus derechos civiles.

Conmueve significativamente ver las fotografías de estos jóvenes localizadas en este espacio de memoria. Todos ellos sonríen a la cámara llenos de vida y de esperanza sin advertir su fatídico destino. El poder de las imágenes nos transmite este sentimiento de afinidad con los protagonistas de las historias y nos permiten solidarizarnos con sus familias. Las fotografías hablan, expresan emociones, construyen narrativas que la propia voz a veces no puede nombrar. Tanto en el pasado como en el presente y pensando en el futuro, las fotografías nos permitirán acercarnos al sentido de lo que quedó fijado en el tiempo como una prueba de los hechos y como una memoria visual que servirá como referente para la humanidad.

Para las nuevas generaciones estas representaciones visuales serán leídas como un registro del pasado. La información que contienen y el contexto que puedan darnos serán un faro para comprender las terribles situaciones que enfrentaron las víctimas y para crear una memoria ejemplar que sirva como marco en la construcción de una consciencia política y social tendiente a la no repetición. 


\section{Referencias}

DA SILVA CATELA, L. Mirar, desaparecer, morir. Reflexiones en torno al uso de la fotografía y los cuerpos como espacios de inscripción de la violencia, en: Clepsidra. Revista Interdisciplinaria de Estudios sobre Memoria. Publicación del Núcleo de Estudios sobre Memoria, Instituto de Desarrollo Económico y Social. ISSN en Línea 2362-2075. Buenos Aires, Argentina: v. 5, n. 11, p. 36-51, 2018.

DIDI-HUBERMAN, G. Arde la Imagen. México: ediciones Ve S.A. de C.V., 2012.

FONTCUBERTA, J. El beso de Judas. Fotografía y verdad. Barcelona: Editorial Gustavo Gili, S.A., 1997.

GIRALDO-LOPERA, M.; TORO-TAMAYO, L. C. (eds.). Tramitar el pasado. Archivos de derechos humanos y museología viva. Medellín: Colección Conflicto y Memoria. Editorial Universidad de Antioquia y Museo Casa de la Memoria, 2018.

GIRALDO-LOPERA, M.; ESTRADA-SIERRA, A.; MESA-PULGARIN, A. M.; CADAVID-ÚSUGA, L. M.; TORO-TAMAYO, L. C.; RESTREPO OSORIO, P. E.; MEJÍA.ACEVEDO, V. Caracterización de los archivos de las organizaciones defensoras de derechos humanos en Medellín. Bogotá: Ministerio de Cultura Convocatoria de Estímulos 2014. Archivo General de la Nación, beca de investigación: "Los archivos y los derechos humanos", 2014.

GIRALDO-LOPERA, M.; TORO-TAMAYO, L. C.; MEJÍA-ACEVEdO, V.; ESTRADA-SIERRA, A. Escuchar, guardar, abrazar: el archivo vivo de la Asociación Caminos de Esperanza Madres de la Candelaria. Medellín: Extrategia Ecoprint SAS, 2015.

GONZÁLEZ CUESTA, B. No ver para ver: el fuera de campo como forma de pensamiento audiovisual, en: Imaginar la realidad. (Ensayos sobre la representación de la realidad en el cine, la televisión y los nuevos medios). Marta Torregrosa Puig (coordinadora). Sevilla: Comunicación Social, cap. 9, 2010.

JELIN, E. La fotografía en la investigación social: algunas reflexiones personales. Memoria y sociedad 16, n. 33, p. 55-67, 2012.

MACHADO DA SILVEIRA, A. C. Midiatizaçāo da tragedia de Santa Maria. A Catástrofe Biopolítica. Santa Maria, RS: FAcos-UFSM, 2018.

RANCIÈRE, J. El espectador emancipado. Buenos Aires: Manantial, 2010.

SOLÓRZANO-ARIZA, A.; TORO-TAMAYO, L. C.; VALLEJO-ECHAVARRÍA, J. C. Memoria fotográfica: la imagen como recuerdo y documento histórico. Revista Interamericana de Bibliotecología, v. 40, n. 1, p. 73-84, 2017. https://doi.org/10.17533/udea.rib.v40n1a07

SONTAG, S. Sobre la fotografía. Bogotá: Alfaguara, 2005.

TAYLOR, D. El archivo y el repertorio. La memoria cultural y performática en las Américas. Santiago de Chile: Ediciones Universidad Alberto Hurtado, 2016.

VAN DIJK, T. A. Ideología y discurso: una introducción multidisciplinaria. Barcelona: Ariel, 2003.

WARBURG, A. Atlas Mnemosyne. En: M. Warnke y F. Checa (eds.). Madrid: Akal, 2010.

WILLIAMS, R. Marxismo y literatura. Barcelona: Península, 2000. 


\section{Fotografías}

Fotografía 1: María Gallego, integrante de la Asociación Caminos de Esperanza Madres de La Candelaria Matrimonio. Proyecto Archivo Vivo: Memorias de Madres. Medellín: Universidad de Antioquia - Museo Casa de la Memoria, 2016.

Fotografía 2: Teresita Gaviria, integrante de la Asociación Caminos de Esperanza Madres de La Candelaria Matrimonio. Proyecto Archivo Vivo: Memorias de Madres. Medellín: Universidad de Antioquia - Museo Casa de la Memoria, 2016.

Fotografía 3: Actividad cultural de la Asociación Caminos de Esperanza Madres de La Candelaria. Medellín: fotografía tomada de la página web de la Asociación, https://redesmadresdelacande.wixsite.com/madresdelacandelaria/galeria?lightbox=imagea9 g, (acceso: 05/09/2019).

Fotografía 4: Carteles utilizados por las madres para sus marchas o plantones en la Iglesia de La Candelaria. Medellín: Fotografía tomada en las instalaciones de la Asociación, 2016. Fotógrafo: Luis Carlos Toro Tamayo.

Fotografía 5: Tienda de la vigilia. Centro de Santa Maria en el estado brasileño de Rio Grande do Sul, Brasil, 2019. Fotógrafo: Luis Carlos Toro Tamayo.

\section{Exposiciones}

Archivo Vivo: Memorias de Madres (2016). Línea Memoria y Sociedad, Universidad de Antioquia, Museo Casa de la Memoria, Asociación Caminos de Esperanza Madres de la Candelaria. Medellín: Museo Casa de la Memoria, 30 de agosto a 29 de octubre de 2016.

Archivo Vivo: Memorias de Madres (2017). Línea Memoria y Sociedad, Universidad de Antioquia, Museo Casa de la Memoria, Asociación Caminos de Esperanza Madres de la Candelaria. Bogotá: Archivo General de la Nación, 13 de junio de 2017.

Exposición virtual MCM (2016). Archivo Vivo: Memorias de Madres. Recuperado de Museo Casa de la Memoria, https://www.museocasadelamemoria.gov.co/Exposiciones/archivosvivos/ (acceso 24 de julio de 2018).

\section{Leyes}

Congreso de Colombia. (20 de diciembre de 2011). Decreto número 48000 de 2011. Ley de Víctimas y Restitución de Tierras y Decretos Reglamentarios. [Ley 1448 de 2011]. DO: 48096. Bogotá. Recuperado de http://www.alcaldiabogota.gov.co/sisjur/normas/Norma1.jsp?i=43043.

Congreso de Colombia. (14 de julio de 2000). Ley General de Archivos. [Ley 594 de 2000]. DO: 44084. Bogotá. 
Congreso de Colombia. (25 de julio de 2005). Ley de Justicia y Paz. [Ley 975 de 2005.]. Obtenido de DO: 45980. Bogotá. Recuperado de http://www.alcaldiabogota.gov.co/sisjur/normas/Norma1.jsp?i=17161.

Congreso de Colombia. (6 de marzo de 2014). Ley de Transparencia y del Derecho de Acceso a la Información Pública Nacional. [Ley 1712 de 2014.]. Bogotá. Recuperado de http://www.alcaldiabogota.gov.co/sisjur/normas/Norma1.jsp?i=56882.

AGN (Autor Corporativo 2002). Formato Único de Inventario Documental - Material Fotográfico, Regulado en septiembre de 2002 según Acuerdo 038, artículo 15 de la Ley General de Archivos 594 de 2000. Colombia: Archivo General de la Nación.

Recebido em: 13/09/2019. Aceito em: 27/09/2019. 